\title{
Pedicle-Lengthening Osteotomy for the Treatment of Lumbar Spinal Stenosis: the Surgical Technique (Pillot Clinical Study)
}

\author{
DOI: 10.17691/sm2018.10.3.7
}

Received May 31, 2018

S.G. Mlyavykh, MD, PhD, Director of the Institute of Traumatology and Orthopedics";

A.E. Bokoy, MD, PhD, Head of the Neurosurgery Department, Institute of Traumatology and Orthopedics';

K.S. Yashin, MD, Junior Researcher, Laboratory of Super-Resolution Microscopy and Gene Technologies, Institute of Biomedical Technologies'; Neurosurgeon, Neurosurgery Department, Institute of Traumatology and Orthopedics 1 ,

D.G. Anderson, MD, Professor, Departments of Orthopaedic and Neurological Surgery2; Clinical Director of the Spine Section, Orthopaedic Research Laboratory²

1Privolzhsky Research Medical University, 10/1 Minin and Pozharsky Square, Nizhny Novgorod, 603005, Russia; ${ }^{2}$ Thomas Jefferson University, 130 S., 9th Street, Philadelphia, PA, 19107, USA

Stenosis of the lumbar spine is a common degenerative disease; its progression leads to a significant restriction in daily activities and quality of life. This pilot study presents a novel minimally invasive technology for surgical correction of lumbar stenosis; the technique involves a widening of the spinal canal and intravertebral foramen by percutaneous bilateral osteotomy of the vertebral pedicles and their subsequent lengthening.

Materials and Methods. Twenty patients with symptomatic lumbar stenosis were included in this prospective study (11 of them with stable anterolisthesis grade I). The patients underwent percutaneous osteotomy with lengthening of the vertebral pedicles at one or two levels. X-ray results were obtained from either standard radiography or computed tomography of the lumbar spine. The baseline patients' condition and the clinical outcomes of the surgical treatment were assessed using a number of validated examination tests, including the Oswestry Disability Index (ODI), the Zurich Claudication Questionnaire (ZCQ), the 10-mm visual-analogue pain scale (VAS), the SF-12 nonspecific quality of life questionnaire (version 2) with the physical (PCS) and mental (MCS) component summary scores. The minimal period of postoperative follow-up was 78 months (6.5 years).

Results. In all cases of surgical interventions, the percutaneous osteotomy proceeded without complications and with a minimal blood loss. As compared with the preoperative period, the patients' quality of life (according to ODI) significantly improved from 48 to 15.5 points over 12 months $(p=0.0002)$ and 5 years $(p=0.0004)$, and up to 20 points in 6 and more years $(p=0.0001)$. The SF- 12 test also showed a statistically significant improvement in the quality of life throughout the observation period, with the exception of the MCS score taken soon (6 weeks) after the surgery. The pain syndrome (according to VAS) significantly diminished both in the back and in the lower extremity from the preoperative 5.8 and 7.4 points to 2.25 and 0.05 points after 5 years $(p=0.0004)$. However, after 6 years or more, the pain syndrome again increased to 3.2 and 2.4 points, respectively, but remained significantly better than that in the preoperative period ( $p=0.04$ and $p=0.0006$, respectively). According to the ZCQ questionnaire, the patients' condition improved from 2.0 points (6 weeks after surgery) to 1.5 points at 12 months $(p=0.01)$ and to 1.67 after 5 years $(p=0.011)$. However, after 6 years or more, the value of $Z C Q$ increased to 1.83 points, which did not significantly differ from the preoperative level $(p=0.14)$.

Conclusion. Percutaneous bilateral osteotomy of the vertebral pedicles followed by their lengthening in patients with symptomatic lumbar spinal stenosis (including stable spondylolisthesis grade I) is a promising innovative technology. This minimally invasive treatment is beneficial primarily for elderly patients and those suffering from comorbidity. The results of this pilot study followed up for more than 6 years indicate a good immediate and encouraging long-term outcome of this treatment.

Key words: spinal stenosis; spinal canal stenosis; closed spine osteotomy; vertebral pedicle-lengthening.

\section{Introduction}

Stenosis of the lumbar spine is a narrowing of the spinal canal and/or intervertebral foramina. The most common cause of stenosis is a degenerative process that results in intervertebral disc herniation, hypertrophy of the facet joints, thickening of the yellow ligament and/ or spondylolisthesis. Stenosis can develop at any level of the lumbar spine, but most often it occurs at the $L_{4}-$ $L_{5}$ segment [1]. The main clinical manifestations of degenerative stenosis are low back pain, radiculopathy or radicular ischemia, and neurogenic intermittent

Corresponding author: Sergey G. Mlyavykh, e-mail: serg.mlyavykh@gmail.com 
claudication, which limits the ability of patients to maintain a vertical posture and move around. In elderly patients with severe stenosis or with severe comorbidity, conservative treatment becomes ineffective with time or brings only temporary improvement [2]. Surgical decompression (with or without associated spondylodesis) leads to a much better outcome as compared with conservative methods [3]. Traditional open surgical interventions, although effective in eliminating the compression of nerve structures, have a number of drawbacks; among them are the risks of significant blood loss, infectious complications, iatrogenic instability, perineural commissures and a long rehabilitation period [4]. In addition, the positive outcome - the pain improvement - can disappear with time and then more complex surgical intervention is needed [5].

Minimally invasive surgical approaches to the treatment of lumbar stenosis have a number of advantages, e.g. a significant reduction in muscle damage and blood loss, as well as a shorter period of hospital stay and rehabilitation. However, because of the flat "learning curve" and the risks of technical complications, surgeons choose to avoid these minimally invasive manipulations in cases of spinal stenosis [610]. The use of interspinous spacers is considered a low invasive option for the treatment of degenerative lumbar stenosis and can work well to result in a significant relief of symptoms in the sitting position [11, 12]. However, a number of studies found these spacers inconsistent for use, with some authors reporting a relatively high incidence of system failure and/or the need for a later revision surgery [13-15].

This work presents a new minimally invasive technology for a surgical removal of lumbar stenosis and an increase in the diameter of the spinal canal and intervertebral foramina by bilateral osteotomy and subsequent lengthening of the vertebral pedicles. This transcutaneous procedure is performed under X-ray control, similar to another surgical procedure vertebroplasty.

The aim of the study was to substantiate this surgical modality and demonstrate its long-term results (clinical and radiological) obtained in patients with symptomatic lumbar stenosis.

\section{Materials and Methods}

This pilot prospective study included 20 patients with symptomatic stenosis of the lumbar spine, who underwent outpatient screening and subsequent elective surgical treatment in the Institute of Traumatology and Orthopedics of the Privolzhsky Research Medical University. The study was conducted in accordance with the Helsinki Declaration (2013) and approved by the local ethics committee. An informed consent has been obtained from each patient.

All patients were operated between January 2009 and
Table 1

Clinical parameters of participating patients

\begin{tabular}{lc}
\hline \multicolumn{1}{c}{ Parameter } & Value \\
\hline The number of patients & 19 \\
\hline Age (years) & $61.7(47-77)$ \\
\hline Sex, male/female & $8 / 11$ \\
\hline Body mass index & $25-29.9(n=10)$ \\
& $>30(n=9)$ \\
\hline $\begin{array}{l}\text { Physical status of patients by ASA classification, } \\
\text { class II/III/IV }\end{array}$ & $7 / 11 / 1$ \\
\hline Spondylolisthesis, none/grade I & $8 / 11$ \\
\hline
\end{tabular}

October 2011. The long-term outcomes ( $\geq 78$ months after surgery) were followed up in 19 patients; one patient died 13 months after the operation from causes not related to the treatment.

The general characteristics of patients are presented in Table. 1. All participants had symptomatic spinal lumbar stenosis and showed no improvement for at least 6 months of conservative treatment.

The study inclusion/exclusion criteria are shown in Table 2.

Evaluation of postoperative results. The treatment outcome was evaluated using several validated tests, including the Oswestry Disability Index (ODI, version 2.0) [16]; the Zurich questionnaire for assessing the quality of life in patients with intermittent claudication (Zurich Claudication Questionnaire, ZCQ) [17, 18]; the 10-mm visual-analogue scale (VAS); the SF-12 scale (version 2) with the physical component score (PCS) and mental component score (MCS) [19]. An assessment of patient's condition was performed 2 weeks before the surgery and 1.5, 3, 6, 9, 12, 24, 60, and 78-96 months after it. During each follow-up visit, we conducted a physical and neurological examination of the patient and also assessed his/her condition using the above standard tests. On visits in months 1.5, 3, 6, and 9 after the operation, an X-ray examination of the lumbar spine in AP and lateral plains was performed. A CT scan of the lumbar spine was run before surgery and 6 months after it. An MRI test was performed only before surgery.

Surgical technique and pedicle-lengthening instruments. In the course of preoperative planning, the dimensions of osteotomy and pedicle-lengthening were determined considering the clinical manifestations. Surgery was performed under general anesthesia $(n=18)$ or regional anesthesia $(n=1)$; a C-arm (model 9800, General Electric, USA) X-ray equipment was used for guidance.

The device (implant) installed during the surgical procedure comprised of a two-section external screw that supports the body and the pedicles of the vertebrae, as well as an internal screw that can shift the ventral and dorsal parts of the outer screw against each other 
Table 2

Inclusion/exclusion criteria for the study

\begin{tabular}{ll}
\hline \multicolumn{1}{c}{ Inclusion criteria } & \multicolumn{1}{c}{ Exclusion criteria } \\
$\begin{array}{l}\text { Sex - male/female } \\
\text { Age - 40-80 years old }\end{array}$ & $\begin{array}{l}\text { History of surgical interventions on the lumbar spine } \\
\text { The presence of spondylolisthesis of grade II and higher }\end{array}$ \\
$\begin{array}{l}\text { Clinical manifestations of stenosis in the lumbar spine area: } \\
\text { severe pain in the buttocks, hips, calves; }\end{array}$ & $\begin{array}{l}\text { Scoliotic deformation of the lumbar spine is greater than } 15^{\circ} \\
\text { neurogenic intermittent claudication or signs of radiculopathy }\end{array}$ \\
$\begin{array}{l}\text { According to MRI/CT with myelography - there are signs of narrowing } \\
\text { of the spinal canal, lateral pockets and/or intervertebral foramen }\end{array}$ & $\begin{array}{l}\text { bisphosphonates, immuno-suppressors) and/or chemotherapy/ } \\
\text { radiotherapy for oncological diseases }\end{array}$ \\
$\begin{array}{l}\text { Within } 6 \text { months, the patient received conservative treatment, including } \\
\text { one or more of the following therapies: NSAID, analgesics, epidural blocks, } \\
\text { physiotherapy }\end{array}$ & $\begin{array}{l}\text { Smoking } \\
\text { History of metabolic disorders of bone tissue (for example, }\end{array}$ \\
$\begin{array}{l}\text { The principal investigator considers the patient a good candidate } \\
\text { for surgical decompression of the spinal canal that can alleviate }\end{array}$ & $\begin{array}{l}\text { osteoporosis) or other diseases that can impede bone healing } \\
\text { in the area of osteotomy (Paget's disease, osteomalacia }\end{array}$ \\
the symptoms & or other osteodystrophies)
\end{tabular}

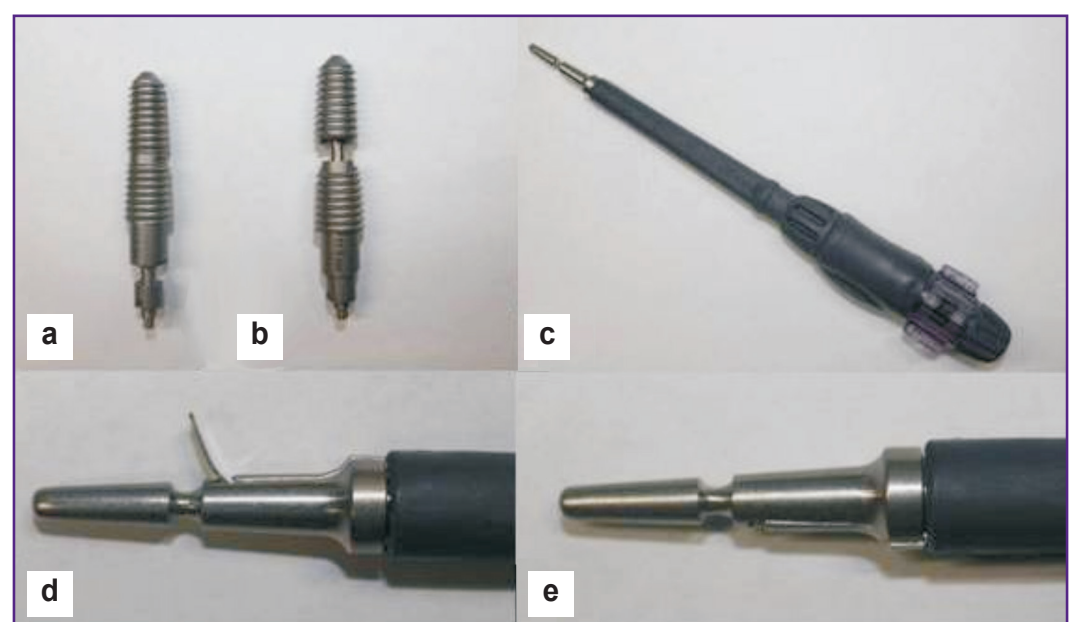

Figure 1. Device for vertebral pedicle-lengthening:

(a) a two-section external screw (folded); (b) after lengthening; (c) instrument (a bone saw) for percutaneous osteotomy with a handle to control the concealed end-point blade; (d) the saw with the blade exposed; (e) the saw in the folded state

(Figure 1). By adjusting the position of the internal screw, one can expand the zone aimed for the osteotomy, and thus increase the diameter of the spinal canal and the intervertebral foramen. Upon completing the distraction procedure in the osteotomy zone, the implants get stabilized. Thereafter, they support the pedicles and keep them elongated until spondylodesis is completed.

The operation procedure. With the patient in prone position and under the X-ray control, projections of the vertebral pedicles on the skin were determined and marked (Figure 2 (a), (b)). In the projections of the pedicle central axis, $10 \mathrm{~mm}$ long linear incisions were made. Then, a guiding rod of $2.7 \mathrm{~mm}$ in diameter was inserted through the central axis of the pedicle into each vertebral body bilaterally (Figure 2 (c)-(e)); along the rod, a cannulated dilator was inserted (Figure 2 (f)). The osteotomy was performed on the basis of the pedicle with the help of an original bone saw, inserted into the newly formed pedicle channel (Figure 1 (c), (d)) under the X-ray control (Figure 2 (g), (h)). This manual bone saw has a lateral retractable blade with a size controlled by the surgeon. By using sectoral rotational movements of the saw, under the X-ray and tactile control, the surgeon performs a stepwise bone resection (with a step of $0.5 \mathrm{~mm}$ ), moving from the pedicle interior towards the outside until the cortical layer is destroyed. Further, the saw blade is concealed and can be moved further to resect other sectors of the pedicle. Upon the completion of the circular pedicle cutting, the saw is removed from the operation field to perform the similar procedure on the contralateral side.

After the bilateral osteotomy of the vertebral pedicles is completed, expandable implants are inserted into the bone channel in such a way that their distal parts are located deeper than the osteotomy zone (see Figure 2 (g), (h)); then follows a simultaneous lengthening of both vertebral pedicles by $4.8 \mathrm{~mm}$ each. The installed implants create a space between the anterior (vertebral body) and the posterior (pedicles, endplates, facet joints) structures of the spinal canal. After an X-ray check, the structure is finally fixed with a special locking nut (Figure 2 (i), (j)). For the step-by-step operation procedure, see the video clip.

Skin incisions are sutured and more local anesthetics applied to reduce the severity of postoperative pain syndrome. There is no need for any additional immobilization in the postoperative period, however, to 


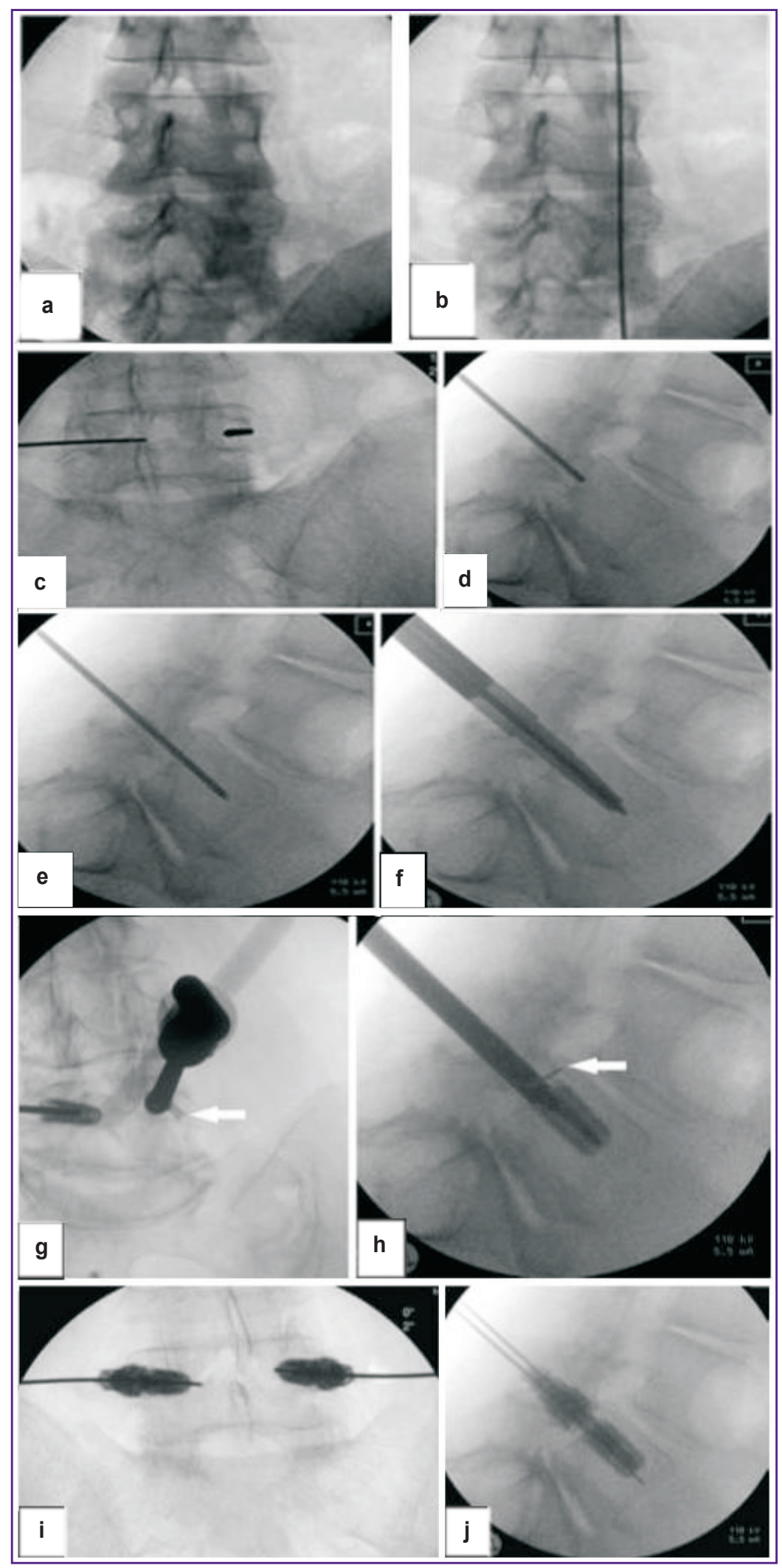

Figure 2. Surgical technique for installing an elongated pedicle

An X-ray image (AP plain) of the pedicles (a) and the guiding rod (b) for marking the pedicle axis projection on the skin; the images in the AP (c) and lateral (d), (e) plains show the stages of the guide movement through the pedicles to the vertebral body; those were followed by the installation of a cannulated dilator in the center of the pedicle (f); the vertebral pedicle osteotomy using a special bone saw under X-ray control in the AP $(\mathrm{g})$ and lateral $(\mathrm{h})$ plains; the devices used for the pedicle-lengthening are shown in the AP (i) and lateral (j) plains 
ensure the optimal healing at the osteotomy site, it is recommended to avoid twisting or bending movements at the lumbar spine for 6 weeks after surgery.

Morphometric analysis. CT scans of the lumbar spine, obtained in the preoperative examination and 6 months after the surgery, were analyzed using the Digital Earthwatch Software package (http://www. lawrencehallofscience.org/gss/rev/ip/). Two experienced vertebrologists evaluated the axial images of the spine at the height of stenosis; the vertebra width was used for the reference. A "rectangle" software tool with the formation of a closed polygon was used for the surface area measurement on each image at every 15-20 points to identify the spinal canal; the volume inside every polygon was calculated in pixels with the help of the software. The spinal canal cross-sectional areas on the preoperative and postoperative CT images were compared using the formula:

$$
\Delta S=\frac{S_{\text {preop }}-S_{\text {postop }}}{S_{\text {preop }}},
$$

where $\Delta S$ - change in the area of the spinal canal $(\%) ; S_{\text {preop }}-$ the preoperative area value; $S_{\text {postop }}-$ the postoperative area value

Statistical analysis. Comparison of the data obtained at the preoperative and postoperative examinations was performed using the Statistica 10.0 software packages. The spinal canal measurements were evaluated with the intra-class correlation coefficient (ICC). The ICC value of $0.90-1.0$ was considered significant; $0.70-$ 0.89 - as good; $0.50-0.69$ - as satisfactory, and $<0.49-$ as poor. The treatment results were compared using the nonparametric Wilcoxon criterion for paired comparisons.

\section{Results}

Description of the surgical interventions. Specifics of surgical interventions including the placement of the implants are presented in Table 3. The single-level bilateral procedure was performed in 10 patients, and the double-level procedure was

Table 3

Installation of implants at different levels of the lumbar spine

\begin{tabular}{lc}
\hline \multicolumn{1}{c}{ Category } & Value \\
\hline Levels, single/double & $10 / 19$ \\
\hline Double-level installation at $L_{3} / L_{4} / L_{5}$ & $2 / 8 / 18$ \\
\hline $\begin{array}{l}\text { Combined installation at several levels: } \\
L_{4} \text { and } L_{5}\end{array}$ & 7 \\
$L_{3}$ and $L_{5}$ & 1 \\
$L_{3}$ and $L_{4}$ & 1 \\
\hline Number of lengthening pedicles, $L_{3} / L_{4} / L_{5}$ & $4 / 16 / 36$ \\
\hline
\end{tabular}

performed also in 10 patients. The $L_{5}$ (19 patients), $L_{4}$ (9 patients) and $L_{3}$ (2 patients) levels were the most common locations. In the double-level procedure, a combination of $L_{4}$ and $L_{5}$ was performed most often (8 patients). The average operation time of the singlelevel procedure (2 pedicles) was $63 \mathrm{~min}$, and that of the two-level procedure (4 pedicles) $-118 \mathrm{~min}$. The average time interval needed to complete an X-ray scan at the single and double level surgery was 2 min $15 \mathrm{~s}$ and $3 \mathrm{~min} 34 \mathrm{~s}$, respectively. The blood loss during all operative interventions was minimal and did not exceed $10 \mathrm{ml}$.

Complications. During the study, no intraoperative complications occurred. In the postoperative period, there was no inflammation in the operation area, no symptoms of nerve root damage, no increase in neurological symptoms, and no patient chose to switch to the open decompression. Adverse events were observed in 4 cases; the most notable were local muscle spasms that appeared within the first post-operation hours and usually resolved within $24 \mathrm{~h}$; no further treatment was required.

In three patients, an incomplete response to the treatment was noted; that was either residual (1 patient) or recurrent (2 patients) lower extremity pain, which might be associated with an incomplete correction of lumbar stenosis. These patients then underwent a standard open surgical intervention 6-18 months later (two patients with concomitant degenerative spondylolisthesis had a posterolateral interbody fusion). During the open surgery, a complete healing of the osteotomy areas in the pedicles was confirmed; also the implants were found stable without affecting any of the surrounding neural structures. In one case, a unilateral instability of the implant was found. In this patient, after a double-level intervention, spinal stenosis was not accompanied by spondylolisthesis; this patient had the highest index of somatic comorbidity (grade IV according to ASA). In-depth examination revealed a marked osteoporosis in the patient, thus ruling out his participation in the study.

Results of the radiological study. All images were analyzed by an independent radiologist. According to AP and lateral X-ray scans taken 1.5, 3, 6, 9, and 12 months after surgery, there were no signs of incompetence, damage or element migration. One patient though developed a screw instability, which was visualized as a $2-\mathrm{mm}$ shadow along the boundaries of the implant (see "Complications"). According to a CT scan taken six months after the closed osteotomy, a bone block was formed in the osteotomy area in all 19 patients (Figure 3). In no case were there any signs of heterotopic ossification in the spinal canal or intervertebral foramen.

Morphometric analysis showed an increase in the cross-section area of the spinal canal in the postoperative period by an average of $15 \%$, with a high degree of inter-expert reliability $(\mathrm{ICC}=0.88)$. 

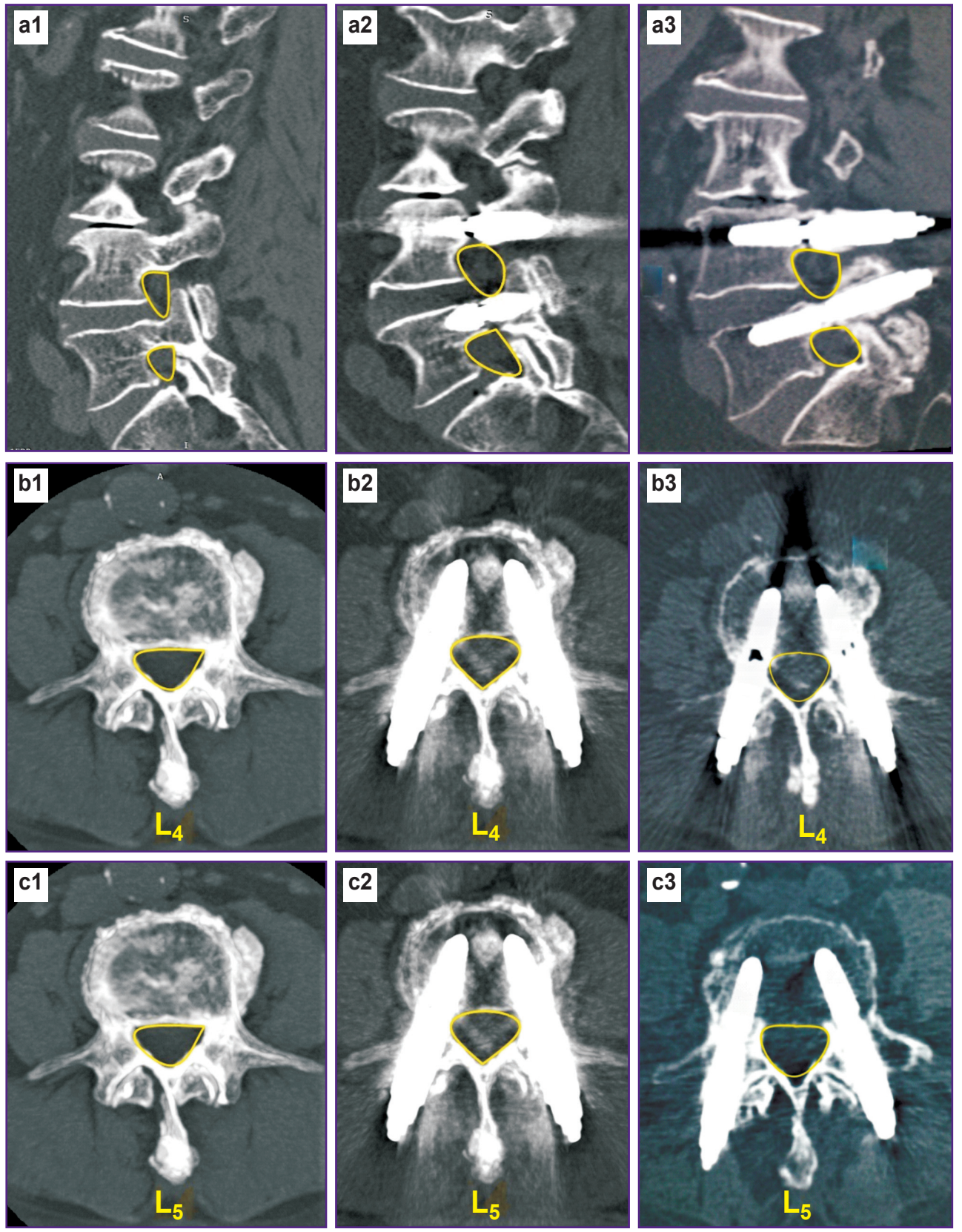

Figure 3. Computed tomography scans of the $L_{4}$ and $L_{5}$ vertebrae pedicles in the sagittal (a1-a3) and axial (b1-b3), (c1-c3) plains

The yellow lines denote the foramen areas of the $L_{4}-L_{5}$ and $L_{5}-S_{1}(a 1-a 3)$ on the left and the spinal canal cross-section area at $L_{4}(b 1-b 3)$ and $L_{5}(c 1-c 3)$ before the operation (a1, b1, c1), immediately after it (a2, b2, c2) and after 6 months (a3, b3, c3); signs of bone fusion in the osteotomy zone can be seen

Clinical outcomes. The clinical examination results are presented in Table 4. According to every assessment test, the patients' condition improved and the symptoms regressed over a period of 5 years. Although patients reported some deterioration in 6 years upon surgery, their quality of life, according to the questionnaires, remained significantly higher than that before the operation (Figure 4).
In comparison with the preoperative period, the patients' quality of life, by the Oswestry score, significantly improved from 48 to 15.5 points at 12 months $(p=0.0002)$ and 5 years $(p=0.0004)$, and to 20 points through 6 and more years $(p=0.0001)$.

The SF-12 scores also provided evidence of a significant improvement in the quality of life in both the physical and mental health components throughout the 
Table 4

Clinical outcomes of percutaneous osteotomy and lengthening of vertebral pedicles (Me [Q1; Q3])

\begin{tabular}{|c|c|c|c|c|c|c|c|}
\hline \multirow{2}{*}{$\begin{array}{l}\text { Time } \\
\text { of testing }\end{array}$} & \multirow{2}{*}{ ODI (score) } & \multicolumn{2}{|c|}{ SF-12 (score) } & \multicolumn{3}{|c|}{ VAS score } & \multirow{2}{*}{$\begin{array}{c}\text { ZCQ } \\
\text { (score) }\end{array}$} \\
\hline & & PCS & MCS & Back pain & Leg pain & Pain at standing & \\
\hline Before surgery & 48. $0[37.7 ; 68.0]$ & $24.4[21.9 ; 28.9]$ & $34.6[27.5 ; 45.8]$ & $5.8[2.7 ; 6.7]$ & $7.4[4.8 ; 9.5]$ & $7.9[4.8 ; 9.9]$ & - \\
\hline 6 weeks & $31.1[17.7 ; 51.1]$ & $33.5[24.3 ; 37.3]$ & $40.9[29.4 ; 47.4]$ & $3.1[2.0 ; 5.1]$ & $3.6[1.0 ; 8.0]$ & $3.8[1.3 ; 7.7]$ & $2.0[1.5 ; 3.2]$ \\
\hline$p$ & 0.0003 & 0.02 & 0.11 & 0.09 & 0.009 & 0.006 & - \\
\hline 6 months & $30.0[15.5 ; 40.0]$ & $33.2[23.4 ; 44.3]$ & $48.2[34.5 ; 53.3]$ & $2.2[1.1 ; 3.8]$ & $2.2[0 ; 4.8]$ & $2.3[0 ; 4.8]$ & $2.0[1.3 ; 3.0]$ \\
\hline$p$ & 0.0002 & 0.011 & 0.048 & 0.008 & 0.0005 & 0.0004 & 0.44 \\
\hline 12 months & $15.5[6.6 ; 42.4]$ & $34.2[25.4 ; 52.5]$ & $50.6[43.7 ; 56.5]$ & $1.8[0.0 ; 3.8]$ & $1.2[0 ; 3.2]$ & $1.4[0 ; 3.9]$ & $1.5[1.0 ; 2.67]$ \\
\hline p & 0.0002 & 0.0022 & 0.0016 & 0.01 & 0.0002 & 0.0002 & 0.01 \\
\hline 5 years & $15.5[4.0 ; 28.2]$ & $34.7[24.2 ; 50.4]$ & $54.1[51.5 ; 56.1]$ & $2.25[0 ; 5.0]$ & $0.5[0 ; 5.3]$ & $0.5[0 ; 5.3]$ & $1.67[1.33 ; 2.5]$ \\
\hline$p$ & 0.0004 & 0.0095 & 0.0006 & 0.019 & 0.0004 & 0.0004 & 0.011 \\
\hline 6 years & $20.0[11.1 ; 35.5]$ & $38.7[31.3 ; 44.5]$ & $49.4[45.9 ; 52.7]$ & $3.2[2.5 ; 5.0]$ & $2.4[0 ; 3.3]$ & $2.4[0 ; 3.3]$ & $1.83[1.33 ; 2.33]$ \\
\hline$p$ & 0.001 & 0.01 & 0.002 & 0.04 & 0.0006 & 0.0006 & 0.14 \\
\hline
\end{tabular}

Notes. Me is the median value; [Q1; Q3] - the values at the $25^{\text {th }}$ and $75^{\text {th }}$ percentiles of normal distribution; $p$ is the Wilcoxon criterion for paired comparisons. Questionnaires: ODI — Oswestry questionnaire, ZCQ - Zurich questionnaire, VAS - visual-analogue scale, SF-12 - quality of life questionnaire with the calculation of physical (PCS) and mental (MCS) health components.

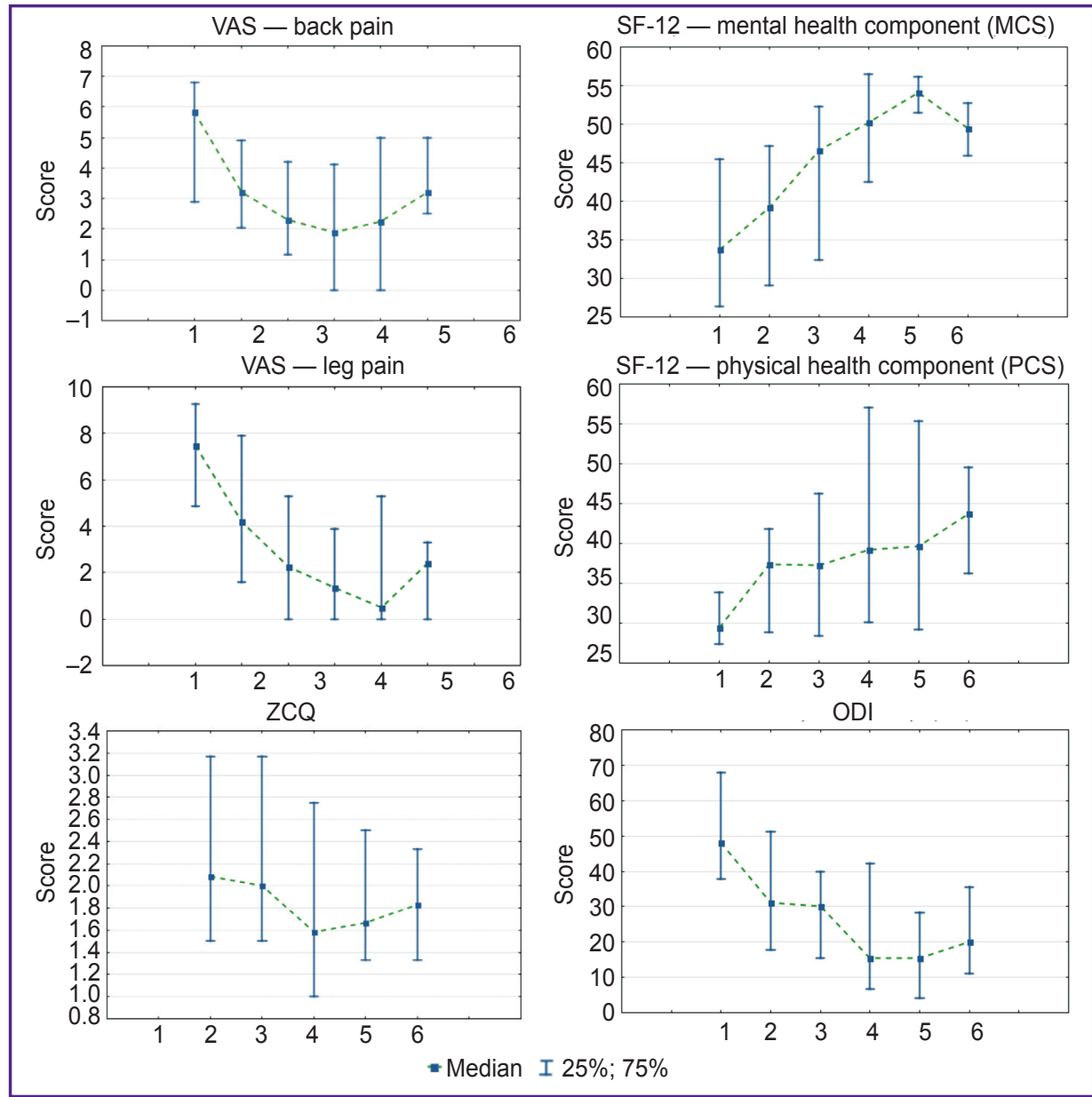

Figure 4. Patients' condition according to the Oswestry test (ODI), Zurich questionnaire (ZCQ), the 10-mm visualanalogue scale (VAS), the SF-12 scale (with indices of physical (PCS) and mental (MCS) health) after closed osteotomy and lengthening of vertebral pedicles:

1 - before surgery; $2-6$ weeks; $3-6$ months; $4-12$ months; $5-5$ years; 6 - more than 6 years 
observation period, except for the mental component in the early postoperative period (6 weeks).

The pain syndrome, according to the VAS, almost completely disappeared both in the back and the leg: it decreased from the pre-operative 5.8 and 7.4 points to 2.25 and 0.05 points after 5 years $(p=0.0004)$. However, after 6 years or more, the pain syndrome partially returned ( 3.2 and 2.4 points by the VAS, respectively), but remained significantly less pronounced as compared to the preoperative period $(p=0.04$ and $p=0.0006$, respectively).

According to the Zurich scale for the quality of life of people with neurogenic intermittent claudication, the improvement in patients' condition from 2.0 points (6 weeks after surgery) to 1.5 points at 12 months $(p=0.01)$ and to 1.67 points after 5 years $(p=0.011)$ was observed. However, after 6 years or more, the ZCQ score changed back to 1.83 points, which did not significantly differ from the preoperative level $(p=0.14)$.

\section{Discussion}

At present, surgical treatment of degenerative stenosis of the lumbar spine is quite common. The traditional method of decompression includes a broad laminectomy, a removal of the yellow ligament and the arcuate joints followed by transpedicular fixation of the respective spinal segment. Such surgical interventions are inevitable in the presence of unstable spondylolisthesis and progressive kyphoscoliotic deformation of the spine. However, in other cases, the rationality of such large-scale operations is questionable, since they have no advantages over normal decompression, but can increase the risk of severe complications [20].

Traditional laminectomy remains the most common method of treating spinal stenosis at the lumbar level and provides satisfactory results in $56-85 \%$ of cases [21]. Yet, this approach has a number of drawbacks, including a significant injury to soft tissue, a risk of significant blood loss, and a wide resection of the posterior structures of the spine [22], which can lead to an iatrogenic instability of this segment. Therefore, alternative approaches, e.g. the use of minimally invasive technologies for the treatment of lumbar stenosis, have been explored. By now, this minimally invasive approach is not considered the gold standard technology because of its rather steep "learning curve" and a significant risk of technical complications [23]. In addition, the available data is still insufficient to compare the open decompression and the minimally invasive technique used in the treatment of stenosis of the lumbar spine [23-25].

In this study, we present an original technique for closed osteotomy and lengthening of the vertebral pedicles; the treatment resulted in an increase in the transverse dimensions of the spinal canal. Yamazaki et al. demonstrated that dural sac decompression was essential for a good clinical outcome of such treatment [26]. Siddiqui et al. showed an increase in the transverse dimensions of the spinal canal by $21 \%$ by using an interosseous X-stop implant, which, according to the authors, led to good clinical results [27]. In our study, persistent improvement in patients' condition was achieved by increasing the size of the spinal canal cross-section up to $15 \%$.

Patients having spinal canal stenosis with spondylolisthesis and without it who underwent conservative treatment or traditional decompression (patients with spondylolisthesis were additionally subjected to instrumental spondylodesis) were included into the SPORT trial $[3,28]$. 12 months after the intervention, patients without spondylolisthesis were found to improve their state by $21.0 \pm 1.0$ points according to Oswestry Disability Index (ODI score before the operation was 43.0) which was statistically significantly higher compared to the group receiving conservative treatment (improvement by $8.9 \pm 1.1$ points). Using the described method we observed the improvement in the patients' condition by 18 points (as evaluated by the Oswestry Disability Index) after 6 months and then persistent improvement by 33 points during 5 years.

In the SPORT trial $[3,28]$, the following complications of the traditional laminectomy were noted: the need for a blood transfusion (in 10\% of cases intraoperative, and in $5 \%$ - postoperative), and the damage to the dura mater - in $9 \%$ of cases. Contrary to that, in the present pilot study on closed osteotomy and lengthening of the pedicles, no damage to the dura mater was observed and no blood transfusion was required. In the SPORT study, a long-term patient follow-up revealed a partial reverse of the positive treatment outcome after 8 years; moreover, in 5 years after the surgery, there were no significant differences between the surgical and conservative treatment groups. In the present study, a trend towards some deterioration in patients' condition was also noted after 6 years or more, but the quality of life, according to the used scales, remained significantly higher vs the preoperative period (see Table 4, Figure 4). The closed pedicle osteotomy with the subsequent pedicle-lengthening results in a decompression of the spinal canal affected by lumbar stenosis without sizable traumatization. Following this min-invasive procedure, the soft tissues and bones of the spine are preserved; the procedure itself is associated with a low risk of intraoperative blood loss or infections. The risk of developing a perineural cicatricial/commissural process is also minimal because no manipulations in the vicinity of nerve roots are performed. By preserving the anatomical integrity of the spine ligaments, the present technique allows the surgeon to prevent the development of instability, a known complication of traditional laminectomy [29, 30].

Closed osteotomy and lengthening of the vertebral pedicles can become a method of choice for chronically ill patients, where the traditional open decompression may be associated with high operation risks. The 
use of frequent X-ray sessions, however, is seen as a disadvantage of the proposed procedure as it adds extra stress on the patient and the operating team; in the future research it should be optimized or replaced with other technologies (navigation, robotic assistance).

Among the limitations of this study are a small number of patients and the absence of a control group. In the future, a large prospective study is needed to determine the relative value of this technology among other treatments for lumbar stenosis. Also, a prolonged follow up is needed to determine whether the positive outcome of this treatment persists.

\section{Conclusion}

Percutaneous osteotomy of the vertebral pedicles with their subsequent lengthening is a novel and promising treatment modality for patients (especially the elderly) with symptomatic lumbar spinal stenosis with or without concomitant grade I spondylolisthesis. The results of this pilot study with a follow up of more than 6 years indicate a good immediate and long-term outcome of this method. Further studies are needed to determine the relative value of this technology among other treatments for lumbar stenosis.

Financial support. This study was partially supported by a grant from Innovative Surgical Designs, Inc.

Conflict of interest. Dr. D.G. Anderson is a consultant to DePuy/Synthes Spine, as well as the owner of Advanced Spinal Intellectual Property and Innovative Surgical Designs, Inc.

\section{References}

1. Amundsen T., Weber H., Lilleås F., Nordal H.J., Abdelnoor M., Magnaes B. Lumbar spinal stenosis. Clinical and radiologic features. Spine (Phila $P a$ 1976) 1995; 20(10): 11781186, https://doi.org/10.1097/00007632-199505150-00013.

2. Amundsen T., Weber H., Nordal H.J., Magnaes B., Abdelnoor M., Lilleâs F. Lumbar spinal stenosis: conservative or surgical management? A prospective 10-year study. Spine (Phila Pa 1976) 2000; 25(11): 1424-1436, https://doi. org/10.1097/00007632-200006010-00016.

3. Weinstein J.N., Tosteson T.D., Lurie J.D., Tosteson A., Blood E., Herkowitz H., Cammisa F., Albert T., Boden S.D., Hilibrand A., Goldberg H., Berven S., An H. Surgical versus nonoperative treatment for lumbar spinal stenosis fouryear results of the Spine Patient Outcomes Research Trial. Spine (Phila Pa 1976) 2010; 35(14): 1329-1338, https://doi. org/10.1097/brs.0b013e3181e0f04d.

4. Fredman B., Arinzon Z., Zohar E., Shabat S., Jedeikin R., Fidelman Z.G., Gepstein R. Observations on the safety and efficacy of surgical decompression for lumbar spinal stenosis in geriatric patients. Eur Spine J 2002; 11(6): 571574, https://doi.org/10.1007/s00586-002-0409-7.

5. Katz J.N., Lipson S.J., Brick G.W., Grobler L.J., Weinstein J.N., Fossel A.H., Lew R.A., Liang M.H. Clinical correlates of patient satisfaction after laminectomy for degenerative lumbar spinal stenosis. Spine (Phila Pa 1976)
1995; 20(10): 1155-1160, https://doi.org/10.1097/00007632199505150-00008.

6. Asgarzadie F., Khoo L.T. Minimally invasive operative management for lumbar spinal stenosis: overview of early and long-term outcomes. Orthop Clin North Am 2007; 38(3): 387399, https://doi.org/10.1016/j.ocl.2007.02.006.

7. Hamasaki T., Tanaka N., Kim J., Okada M., Ochi M., Hutton W.C. Biomechanical assessment of minimally invasive decompression for lumbar spinal canal stenosis: a cadaver study. J Spinal Disord Tech 2009; 22(7): 486-491, https://doi. org/10.1097/bsd.0b013e31818d7dc9.

8. Podichetty V.K., Spears J., Isaacs R.E., Booher J., Biscup R.S. Complications associated with minimally invasive decompression for lumbar spinal stenosis. J Spinal Disord Tech 2006; 19(3): 161-166, https://doi.org/10.1097/01. bsd.0000188663.46391.73.

9. Rahimi-Movaghar V., Rasouli M.R., Vaccaro A.R. Patient outcomes vs a minimally invasive approach in lumbar spinal stenosis: which is more important? Neurosurgery 2010; 67(4): E1180, https://doi.org/10.1227/neu.0b013e3181ee432f.

10. Yoshimoto M., Takebayashi T., Kawaguchi S., Tsuda H., Ida K., Wada T., Suzuki D., Yamashita T. Minimally invasive technique for decompression of lumbar foraminal stenosis using a spinal microendoscope: technical note. Minim Invasive Neurosurg 2011; 54(03): 142-146, https://doi. org/10.1055/s-0031-1279716.

11. Zucherman J.F., Hsu K.Y., Hartjen C.A., Mehalic T.F., Implicito D.A., Martin M.J., Johnson D.R. ${ }^{\text {nd }}$, Skidmore G.A., Vessa P.P., Dwyer J.W., Puccio S.T., Cauthen J.C., Ozuna R.M. A multicenter, prospective, randomized trial evaluating the $X$ STOP interspinous process decompression system for the treatment of neurogenic intermittent claudication: two-year follow-up results. Spine (Phila Pa 1976) 2005; 30(12): $1351-$ 1358, https://doi.org/10.1097/01.brs.0000166618.42749.d1.

12. Zucherman J.F., Hsu K.Y., Hartjen C.A., Mehalic T.F., Implicito D.A., Martin M.J., Johnson D.R. ${ }^{\text {nd }}$, Skidmore G.A., Vessa P.P., Dwyer J.W., Puccio S., Cauthen J.C., Ozuna R.M. A prospective randomized multi-center study for the treatment of lumbar spinal stenosis with the $X$ STOP interspinous implant: 1-year results. Eur Spine J 2004; 13(1): 22-31, https:// doi.org/10.1007/s00586-003-0581-4.

13. Bowers C., Amini A., Dailey A.T., Schmidt M.H. Dynamic interspinous process stabilization: review of complications associated with the X-Stop device. Neurosurg Focus 2010; 28(6): E8, https://doi.org/10.3171/2010.3.focus1047.

14. Brussee P., Hauth J., Donk R.D., Verbeek A.L., Bartels R.H. Self-rated evaluation of outcome of the implantation of interspinous process distraction (X-Stop) for neurogenic claudication. Eur Spine J 2008; 17(2): 200-203, https://doi.org/10.1007/s00586-007-0540-6.

15. Kim D.H., Tantorski M., Shaw J., Martha J., Li L., Shanti N., Rencu T., Parazin S., Kwon B. Occult spinous process fractures associated with interspinous process spacers. Spine (Phila Pa 1976) 2011; 36(16): E1080-E1085, https://doi.org/10.1097/brs.0b013e318204066a.

16. Pratt R.K., Fairbank J.C., Virr A. The reliability of the Shuttle Walking Test, the Swiss Spinal Stenosis Questionnaire, the Oxford Spinal Stenosis Score, and the Oswestry Disability Index in the assessment of patients with lumbar spinal stenosis. Spine (Phila Pa 1976) 2002; 27(1): 84-91, https://doi. org/10.1097/00007632-200201010-00020.

17. Stucki G., Daltroy L., Liang M.H., Lipson S.J., Fossel A.H., Katz J.N. Measurement properties of a self- 
administered outcome measure in lumbar spinal stenosis. Spine (Phila Pa 1976) 1996; 21(7): 796-803, https://doi. org/10.1097/00007632-199604010-00004.

18. Stucki G., Liang M.H., Fossel A.H., Katz J.N. Relative responsiveness of condition-specific and generic health status measures in degenerative lumbar spinal stenosis. J Clin Epidemiol 1995; 48(11): 1369-1378, https://doi. org/10.1016/0895-4356(95)00054-2.

19. Byval'tsev V.A., Belykh E.G., Sorokovikov V.A., Arsent'eva N.I. The use of scales and questionnaires in vertebrology. Zhurnal nevrologii i psikhiatrii im. S.S. Korsakova 2011; 111(9 Pt 2): 51-56.

20. Deyo R.A., Mirza S.K., Martin B.I., Kreuter W., Goodman D.C., Jarvik J.G. Trends, major medical complications, and charges associated with surgery for lumbar spinal stenosis in older adults. JAMA 2010; 303(13): 12591265, https://doi.org/10.1001/jama.2010.338.

21. Cho D.Y., Lin H.L., Lee W.Y., Lee H.C. Split-spinous process laminotomy and discectomy for degenerative lumbar spinal stenosis: a preliminary report. J Neurosurg Spine 2007; 6(3): 229-239, https://doi.org/10.3171/spi.2007.6.3.229.

22. Mobbs R.J., Li J., Sivabalan P., Raley D., Rao P.J. Outcomes after decompressive laminectomy for lumbar spinal stenosis: comparison between minimally invasive unilateral laminectomy for bilateral decompression and open laminectomy: clinical article. J Neurosurg Spine 2014; 21(2): 179-186, https://doi.org/10.3171/2014.4.spine13420.

23. Mannion R.J., Guilfoyle M.R., Efendy J., Nowitzke A.M., Laing R.J., Wood M.J. Minimally invasive lumbar decompression: long-term outcome, morbidity, and the learning curve from the first 50 cases. J Spinal Disord Tech 2012; 25(1): 47-51, https://doi.org/10.1097/bsd.0b013e31820baa1e.

24. Fu K.M., Smith J.S., Polly D.W. Jr., Perra J.H., Sansur C.A., Berven S.H., Broadstone P.A., Choma T.J., Goytan M.J., Noordeen H.H., Knapp D.R. Jr., Hart R.A., Zeller R.D., Donaldson W.F. $3^{\text {rd }}$, Boachie-Adjei O., Shaffrey C.I. Morbidity and mortality in the surgical treatment of 10,329 adults with degenerative lumbar stenosis. J Neurosurg
Spine 2010; 12(5): 443-446, https://doi.org/10.3171/2009.11. spine09531.

25. Ng K.K.M., Cheung J.P.Y. Is minimally invasive surgery superior to open surgery for treatment of lumbar spinal stenosis? A systematic review. J Orthop Surg (Hong Kong) 2017; 25(2): 2309499017716254, https://doi. org/10.1177/2309499017716254.

26. Yamazaki K., Yoshida S., Ito T., Toba T., Kato S., Shimamura T. Postoperative outcome of lumbar spinal canal stenosis after fenestration: correlation with changes in intradural and extradural tube on magnetic resonance imaging. J Orthop Surg (Hong Kong) 2002; 10(2): 136-143, https://doi. org/10.1177/230949900201000206.

27. Siddiqui M., Karadimas E., Nicol M., Smith F.W., Wardlaw D. Influence of $X$ Stop on neural foramina and spinal canal area in spinal stenosis. Spine (Phila Pa 1976) 2006; 31(25): 2958-2962, https://doi.org/10.1097/01. brs.0000247797.92847.7d.

28. Weinstein J.N., Lurie J.D., Tosteson T.D., Zhao W., Blood E.A., Tosteson A.N., Birkmeyer N., Herkowitz H., Longley M., Lenke L., Emery S., Hu S.S. Surgical compared with nonoperative treatment for lumbar degenerative spondylolisthesis: four-year results in the Spine Patient Outcomes Research Trial (SPORT) randomized and observational cohorts. J Bone Joint Surg Am 2009; 91(6): 1295-1304, https://doi.org/10.2106/jbjs.h.00913.

29. Lee M.J., Bransford R.J., Bellabarba C., Chapman J.R., Cohen A.M., Harrington R.M., Ching R.P. The effect of bilateral laminotomy versus laminectomy on the motion and stiffness of the human lumbar spine: a biomechanical comparison. Spine (Phila Pa 1976) 2010; 35(19): 1789-1793, https://doi. org/10.1097/brs.0b013e3181c9b8d6.

30. Tai C.L., Hsieh P.H., Chen W.P., Chen L.H., Chen W.J., Lai P.L. Biomechanical comparison of lumbar spine instability between laminectomy and bilateral laminotomy for spinal stenosis syndrome - an experimental study in porcine model. BMC Musculoskelet Disord 2008; 9: 84, https://doi. org/10.1186/1471-2474-9-84. 